\title{
CONFLITOS ENQUADRADOS COMO BULLYING: CATEGORIA QUE AUMENTA TENSÓES E IMPOSSIBILITA ANÁLISES
}

CONFLICTS FRAMED AS BULLYING: CATEGORY THAT INCREASES TENSIONS AND PRECLUDES ANALYSIS

CONFLICTOS ENCUADRADOS COMO BULLYING: CATEGORÍA

QUE AUMENTA TENSIONES E IMPOSIBILITA ANÁLISIS

Giovanna Marafon* Estela Scheinvar** Maria Livia do Nascimento***

\section{Resumo}

Este texto busca debater o enquadramento de certas relações em uma categoria nomeada bullying e sua emergência no contexto brasileiro, pensando-a como uma prática contemporânea que atravessa sobretudo a escola. Coloca-se em análise a lógica penal inscrita nessa prática identitária, sustentada nos fundamentos do Estado de Direito, que define funçóes para os especialistas e alimenta a criação de leis. Esta é uma marca da sociedade punitiva que vivemos atualmente e na qual o agressor é conduzido pelos trajetos da judicialização e da medicalização, visto como um possível delinquente, e a vítima é despotencializada. Constata-se um ajustamento dos fenômenos de população aos processos econômicos: o bullying se inscreve na lógica da norma, como diz Foucault, própria das artes de julgar.

Palavras-chave: bullying; Estado de Direito; escola; judicializaçáo.

* Universidade Federal Fluminense, Rio de Janeiro, RJ, Brasil.

** Universidade Federal Fluminense, Rio de Janeiro, RJ, Brasil. Universidade do Estado do Rio de Janeiro, Rio de Janeiro, RJ, Brasil.

*** Universidade Federal Fluminense, Rio de Janeiro, RJ, Brasil. 


\section{Abstract}

This text is interested in debating the framework of certain relationships in a category named bullying and its emergency in the Brazilian context, understood as a contemporary practice that overdresses specially the school. It puts in analysis the penal logic registered in this practice of identity, having as reference the fundaments of the State of Rights, which define functions for specialists and feed the construction of laws. This is a mark of the present punitive society, in which the aggressor is conduced through the roads of the judicialization and medicalization, seen as a possible delinquent, and the victim is despotencialized. It can be seen an adjustment of the phenomena of population according to the economical processes: bullying is inscribed in the logic of the norm, as says Foucault, own of the arts of judging.

Keyword: bullying; State of Rights; school; judicialization.

\section{Resumen}

Este texto busca debatir el encuadramiento de ciertas relaciones en una categoría nombrada bullying y su emergencia en el contexto brasileño, pensándola como una práctica contemporánea atravesada sobre todo en la escuela. Planteamos el análisis de la lógica penal inscrita en esa práctica identitaria, sostenida en los fundamentos del Estado de Derecho, que define funciones para los especialistas y alimenta la creación de leyes. Esta es una marca de la sociedad punitiva en la que vivimos actualmente y en la cual el agresor es conducido por los trayectos de la judicialización y de la medicalización, asumido como un posible delincuente y la víctima es despotencializada. Constatamos un ajuste de fenómenos de población a los procesos económicos: el bullying se inscribe en la lógica de la norma, como dice Foucault, propia de las artes de juzgar.

Palabras clave: bullying; Estado de Derecho; escuela; judicialización.

\section{Emergência de uma categoria}

Este texto busca debater o enquadramento de certas relaçóes em uma categoria nomeada bullying e sua emergência no contexto brasileiro. Atualmente as práticas enquadradas como bullying atravessam sobretudo a escola, porém alcançam outros estabelecimentos de atendimento à criança e ao adolescente como, por exemplo, os conselhos tutelares. Como o bullying vem sendo definido? Que sentidos vem implantando nos espaços onde se diz que ele ocorre? Como sua 
emergência explosiva em terras brasileiras pode ser pensada? Que forças o têm sustentado como campo de saber-poder? O que a lei de mercado e a lógica capitalista têm a ver com isso? A que serve essa recente denominação de práticas de conflito, dificuldades, diferenças entre escolares, que sempre existiram, e sempre foram resolvidas e administradas nos próprios movimentos e fluxos do cotidiano sem uma ideia de julgamento?

Para pensar a emergência dessa denominação no Brasil não se pode deixar de referir seu caráter de produto importado, com proveniência dos países escandinavos e, posteriormente, do Japão, Inglaterra, Espanha, Portugal, Canadá e Austrália, dentre outros, chegando ao Brasil diretamente da cultura estadunidense ${ }^{1}$ e incorporando uma palavra da língua inglesa que não tem equivalência no português.

Convém remontar ao percurso das pesquisas que divulgaram o bullying. Para isso há que se referir à publicação do livro intitulado Bullying at school: what we know and what we can do (Bullying na escola: o que sabemos e o que podemos fazer), em 1993, de Dan Olweus. Esta obra amplia uma formulação anterior do autor em coautoria com E. Roland, publicada em Oslo em 1983 e intitulada Mobbning. Nessa primeira obra são apresentadas duas partes fundamentais às análises sobre bullying incorporadas no livro de 1993: What we know about bullying (O que sabemos sobre bullying) e What we can do about bullying (O que podemos fazer sobre bullying). Nesse segundo livro de 1993 Olweus acrescenta mais duas partes: Effects of the intervention program (Efeitos do programa de intervenção) e Additional practical advice and a core program (Orientação prática adicional e um programa central) que se tornaram uma grande referência para as produçóes seguintes sobre o assunto, principalmente no Brasil, em termos de definiçóes, encaminhamentos, ideias de programas padronizados para intervenções em escolas e recomendaçóes aos pais e professores.

Para realizar o programa por ele desenvolvido e colocar em prática suas orientaçóes, Olweus contou com apoio do Ministério da Educação da Noruega, do Conselho Norueguês para a Pesquisa Social (NAVF-RSF) e da Delegação Sueca para a Pesquisa Social (DSF) que, em várias fases, financiaram o projeto. Parte desse projeto foi desenvolvida enquanto Olweus era pesquisador no Centro de Estudos Avançados em Ciências do Comportamento, em Stanford, Estados Unidos, o que justifica a abordagem metodológica estadunidense centrada na mudança de comportamentos.

Olweus (1993) afirma haver um momento que marcou a preocupação das escolas e dos pais com o que se convencionava chamar bullying. De acordo com esse autor foi a publicação, em um jornal ao final de 1982, de matéria referindo que três meninos, com idades entre 10 e 14 anos, do nordeste da Noruega, ha- 
viam cometido suicídio, "in all probability as a consequence of severe bullying by peers" (provavelmente, como consequência da grave intimidação por parte de colegas) (Olweus, 1993, p. 2). Tal informação estabeleceu um forte estado de tensão nas mídias e no público em geral em relação a essa nova categoria que se propunha a explicar tais acontecimentos. Tendo desencadeado uma série de reações em relação ao que passou a se chamar bullying, o resultado final foi uma campanha nacional contra os problemas de agressores e vítimas nas escolas primárias, secundárias e o equivalente aos anos iniciais do ensino médio lançada pelo Ministério da Educação da Noruega em 1983.

No entanto, é interessante registrar como livros brasileiros atuais que divulgam o bullying afirmam que "os estudos de Olweus não tiveram muito impacto na época, a não ser sobre poucos núcleos de pessoas interessadas" (Chalita, 2008, p. 102). E mais: "o medo que tomou conta de pais e educadores noruegueses foi, paradoxalmente, combustível para o entusiasmo de Olweus, porque, para ele, o bullying era um mal a combater" (Chalita, 2008, p. 103).

Poucas décadas depois, com a circulação das pesquisas e de seus respectivos resultados, a questáo bullying passou a ser colocada nos seguintes termos:

Nos diversos países, o despertar para essa realidade se deve ao trabalho de pesquisadores e estudiosos do assunto. Os estudos resultantes muito têm contribuído para a conscientização de pais e profissionais das áreas de educação, saúde e segurança pública, que passaram a se interessar e estudar o tema, levando em conta principalmente suas consequências danosas para os envolvidos (Fante \& Pedra, 2008, p. 52).

Foi, portanto, enquanto categoria criada pelo regime de pesquisas comportamentalistas e da divulgação de seus resultados no intuito de modificar os comportamentos indesejados que se deu a continuidade aos investimentos em torno do chamado bullying, respondendo de maneira universalizante a problemas já anunciados. Como o fenômeno pesquisado não cessou de ser divulgado e incentivado o seu mapeamento, a Organização Mundial da Saúde (OMS) apresentou o estudo Health Behaviour in School-aged Children (HBSC) study international report from the 2001/2002 survey (Comportamento saudável de crianças em idade escolar - relatório de estudo internacional da pesquisa de 2001/2002). Esse estudo internacional foi publicado em 2004 pelo escritório regional europeu da World Health Organization (WHO) e seus resultados indicam que a pesquisa foi realizada com 162.306 jovens escolares de três idades sequenciais $-11,13$ e 15 anos -, de 35 países e regióes, incluindo os continentes americano e europeu. 
No relatório da WHO, o subcapítulo intitulado Bullying, physical fighting and victimizacion (Bullying, agressão física e vitimização), escrito por Wendy Craig e Yossi Harel (2004), considera necessário que uma definição de bullying preceda às análises, sublinhando o que era e o que não era bullying. Nesse caso, portanto, à definição de bullying apresentada pela própria pesquisa seguiam-se duas questóes tomadas de empréstimo das pesquisas desenvolvidas por Olweus anteriormente e publicadas em 1983. A primeira pergunta questionava a cada jovem com que frequência havia sofrido bullying na escola nos últimos meses e a seguinte com que frequência havia tomado parte na prática de bullying contra outro(s) estudante(s) na escola nos últimos meses.

As opçóes de resposta para ambas as perguntas eram quase as mesmas: "não sofri bullying ou não pratiquei bullying contra outro estudante na escola nos últimos meses", "aconteceu somente uma ou duas vezes", "duas ou três vezes por mês", "em torno de uma vez por semana" ou "várias vezes por semana”. Um item específico abordava o "comportamento agressivo nos últimos doze meses" e tinha nas opçóes de resposta a frequência: "não me envolvi em brigas físicas", "uma vez", "duas vezes", "três vezes", ou "quatro vezes ou mais". Jovens que indicaram terem se envolvido em alguma briga física nos últimos doze meses foram identificados como "fighters" (o que pode ser traduzido por lutadores, briguentos e/ou agressivos).

No que diz respeito ao bullying, os resultados do estudo podem ser resumidos da seguinte forma: 35\% dos jovens indicaram que estiveram envolvidos na prática de bullying nos meses anteriores. As percentagens variavam entre os 30\% para os jovens de 11 anos; 38\% para os de 13 anos e 36\% para os de 15 anos. $\mathrm{O}$ estudo levantou ainda que existia uma maior incidência nas práticas de bullying aos 13 anos e que era mais frequente nos meninos do que nas meninas. Ao utilizar-se dessas informaçóes em sua dissertação de Mestrado em Psicologia Forense, apresentada ao Instituto Nacional de Medicina Legal - Faculdade de Medicina da Universidade do Porto, Ferraz (2008, p. 36) afirma que: "Os números são importantes para demonstrar a exactidão desta realidade".

Questionamos os efeitos dessas pesquisas e a forma como elas foram realizadas, divulgadas, e seus usos por novos pesquisadores que possivelmente as tenham tomado como fontes verdadeiras que demonstrariam a "exatidão" de uma realidade - o que, por sua vez, produz realidades. $\mathrm{O}$ que se faz, pois os saberes que as orientam e aqueles que elas produzem não são neutros, nem desinteressados, estando atravessados por relaçóes de poder. Propomo-nos colocar em análise essas pesquisas e recusamos a naturalização do que se convencionou chamar bullying porque nos interessa pensar sua emergência como uma categoria cujo efeito é produzir um regime de verdade ${ }^{2}$. 


\section{Lógicas presentes na categoria bullying}

Pela importação do nome e das práticas que o acompanham, o bullying tem sido caracterizado, em um primeiro momento no espaço escolar ${ }^{3}$, por comportamentos ditos violentos que se dáo de forma insistente e intencional, e nos quais são identificados vítimas e agressores.

$\mathrm{O}$ american way of life - paradigma da sociedade liberal - estabelece uma lógica de vencedores e perdedores, seguindo o modelo de competitividade do capitalismo, segundo o qual para que alguns ganhem outros precisam perder. Assim, nessa cultura, valores hegemônicos de beleza, condutas, poder aquisitivo e competências fazem parte da vida dos vencedores; ao passo que para os perdedores, identificados como não possuidores de tais características, restam a sensação de estar fora do lugar, as discriminaçóes e o insucesso. No terreno escolar e no universo infanto-juvenil de algumas regiôes do Brasil essas classificaçóes tomaram as denominaçôes de populares e impopulares, sendo os populares aqueles que "se dão bem", são admirados, têm sucesso entre os colegas, circulam com facilidade e, o que é importante para a discussão sobre bullying, destacam-se atuando pela truculência, hostilidade e altivez; enfim, por práticas que têm como perspectiva a anulação, a humilhação ou a desqualificação do outro. Dessa maneira, pertencem a este grupo tanto os fortes e valentões (bullies), quanto as meninas mais bonitas e bem vestidas no estilo patricinhas. Por não se enquadrarem nos padrôes de popularidade, os ditos perdedores sofrem apelidos, piadas, provocaçóes e violência física.

Essa forma de organização socioescolar chega até o Brasil, dentre outras possibilidades, através de séries e filmes produzidos nos Estados Unidos e do cyber espaço, todos com grande penetração entre crianças e jovens brasileiros. Entretanto, o que deve ser pensado é que, neste particular, construçóes subjetivas foram aproximando países com condiçóes, culturas e práticas escolares tão diversificadas. Em suma, interrogamos: como essa forma de relacionamento popular/ impopular migrou para nossas escolas, criando um território propício à emergência de uma prática que opera por meio do que vem sendo chamado bullying? As brincadeiras de gosto duvidoso sempre existiram entre as crianças e, portanto, sempre tiveram presença na escola brasileira, sendo resolvidas com escaramuças entre dois, às vezes mais, chegando mesmo às vias de fato de socos e pontapés, mas nunca atingindo o lugar da classificação, da denominação, do enquadramento, do controle dos corpos que a categoria bullying estabelece e define. Eram meninos que brigavam ou meninas que se hostilizavam e resolviam entre si suas contendas. Também havia espaço para o acidente, como quando uma estudante 
do ensino fundamental - de acordo com o relato de uma jovem universitária, em uma discussão em sala de aula -, ao participar de uma brincadeira coletiva, foi empurrada e quebrou os dois braços. De acordo com ela, as amigas a acolheram visitando-a, dando suporte na escola e decidiram, sem interferência de adultos, mudar as regras do jogo. Como a própria acidentada diz, hoje ela e a colega seriam vistas como se fizessem parte de uma situação necessariamente violenta, facilmente classificada como sendo bullying, com lugar para uma ser identificada como a vítima e a outra como agressora, e não poderiam ter mantido livremente uma amizade.

Claro que tais episódios em muitos casos eram vividos com sofrimento, e às vezes com a interferência dos adultos, mas sempre livres da objetivação que uma formulação identitária impóe. Além disso, era comum o escape: "o quatro olhos" que se saía bem nos estudos e por isso criava para si um território, procurando se encaixar em um outro lugar; a garota mais tímida tida como menos bela que escolhia a aula de música para mostrar suas virtudes...; enfim, historicamente as diferenças e dificuldades tiveram mais espaço para serem tratadas em suas singularidades, produzindo novos territórios, tão singulares quanto as relaçóes das quais emergiam.

$\mathrm{O}$ enquadramento de condutas sempre traz efeitos. Nesse caso, os diferentes modos de viver uma situação de enfrentamento e de tensôes advindas de provocaçóes corriqueiras entre alunos no espaço escolar e as diferentes formas de resolvê-los foram reduzidos à forma bullying, retirando todo o caráter plural e ao mesmo tempo singular, criativo, dos agenciamentos coletivos que constituem o viver. $\mathrm{O}$ exercício moderno de poder, o biopoder, pode ser visto com clareza quando o tema é bullying. Ao separar os sujeitos da situação em duas categorias estanques, a de vítima e a de agressor, impóem-se dois caminhos. O agressor é conduzido pelos trajetos da judicialização e da medicalização. Visto como um possível delinquente e até um psicopata em potencial, entende-se que o melhor é punir e medicalizar, sendo responsabilizado ou ameaçado por meio de esferas judiciais ou extrajudiciais, como no caso dos conselhos tutelares e da polícia, por exemplo. À chamada vítima cabe, da mesma forma, a linha jurídica para se defender, embora ela também não escape da imediata patologização, sendo diagnosticada em quadros de síndrome do pânico, fobia escolar, depressão, baixa autoestima etc.

Em torno de acontecimentos nomeados por bullying têm-se identificado movimentos entre juristas, áreas policiais, pais, médicos, equipes de assistência social, diretores de escolas na busca por formas de reparação que passem pelo judiciário. Mais uma prática de judicialização da vida, marca da sociedade punitiva 
que vivemos atualmente. Indo nessa direção, o Estado do Rio de Janeiro promulgou em 20 de setembro de 2010 a Lei No 5824, que modifica a lei anterior No 4725/20064, afirmando: "Fica criada obrigação de notificação compulsória à autoridade policial e ao Conselho Tutelar da localidade, por parte das direçóes dos estabelecimentos de ensino e de saúde públicos e privados, localizados no Estado do Rio de Janeiro, nos casos de violência contra a criança e o adolescente".

Com isso, vemos as atividades legislativas aumentarem em termos da criação de mecanismos que têm por finalidade assegurar as denúncias dos "casos de violência contra a criança e o adolescente", não se restringindo ao conselho tutelar como recurso já previsto pelo Estatuto da Criança e do Adolescente. Tais atividades vão além ao estabelecer a obrigatoriedade de notificação compulsória também à polícia. O que é mais impactante nesse movimento é o efeito dessa lei na mídia carioca em 2010, que fez com que aumentasse a procura por entrevistas de especialistas sobre o assunto violência na escola. Afirmava-se o discurso da lei que obrigava as escolas a denunciarem compulsoriamente as situaçóes de bullying à polícia e ao conselho tutelar. Desse modo, a forma mais visível que passava a ser identificada como sinônimo de violência contra a criança e o adolescente nas escolas era o bullying. Esse movimento não acontecia de forma isolada, pois no ano anterior, o município do Rio de Janeiro já havia aprovado a Lei No 5.089, de 6 de outubro de 2009, que "dispóe sobre a inclusão de medidas de conscientização, prevenção e combate ao Bullying escolar no projeto pedagógico elaborado pelas escolas públicas do Município do Rio de Janeiro e dá outras providências".

Tais determinaçóes legais produzem criminalizaçáo e judicialização, retirando dos sujeitos envolvidos e da escola a potência de resolução de seus problemas. Cabe ressaltar que, por ser uma construçáo subjetiva, esse desejo por punição e normatizaçóes legais é cada vez mais demandado pelos envolvidos e pelas escolas, que junto com outros segmentos, como a mídia, o Poder Legislativo, os órgãos públicos, clamam por intervençôes jurídicas e policiais nas relaçôes cotidianas. A partir dessa lógica, no município do Rio de Janeiro o antigo inspetor escolar passou a ser denominado "agente educador", fazendo-nos indagar se os novos termos não estariam mais próximos do linguajar policialesco. O que passa a qualificar a ação desse profissional? Sobressai a ótica educacional, que envolve ações pedagógicas com vistas a uma convivência mais solidária, ou a ótica penal, preocupada em inibir certos comportamentos por meio da ameaça e do castigo? Um dos efeitos desse quadro de configuraçôes sobre o bullying é a alimentação de um ambiente punitivo de fiscalização intensa e a produção de especialistas que vão conduzir as discussóes sobre seu diagnóstico, possíveis formas de atendimento, orientaçóes a pais, escolares, professores, sempre a partir de pon- 
tuações legitimadas como científicas e de verdades estabelecidas. A partir de suas competências técnicas se apressam em apontar a melhor maneira de encaminhar as situaçóes ditas de bullying.

O lugar que ocupamos na discussão desse tema se faz a partir de nossas experiências junto a conselhos tutelares como orientadoras de estágio de alunos de graduação em psicologia e como docentes em cursos de formação de professores. Apontamos também para a participação em fóruns de debates no campo da psicologia perante a demanda crescente para entrevistas na mídia em geral e nas quais se espera que o psicólogo fale como especialista sobre bullying. Tais demandas vêm sendo pautadas na mídia a partir de novas situaçôes identificadas como bullying, e passam a ser noticiadas com grande carga de sensacionalismo, causando temor e produzindo uma subjetividade engendrada pelo perigo social ao se frequentar o espaço escolar. As perguntas passam a ser feitas em termos de "como prevenir", "como combater", "como evitar" etc. No entanto, chama-nos a atenção que os casos relatados pelas escolas sejam enquadrados pelo modo de subjetivação dominante, que classifica os sujeitos envolvidos ou como vítima ou como agressor.

Ao mesmo tempo, há um movimento no sentido de questionar as já aceitas verdades sobre bullying, problematizando seus efeitos e fazendo pensar outras possíveis intervençóes, a partir do espaço escolar, que prescindam dessa identificação, mas que não deixem de atentar para as situaçóes, tantas vezes aflitivas, nas relações do cotidiano escolar.

\section{O uso de uma categoria como enquadramento: formatando o bullying}

Percebemos uma naturalização na classificação do que seria bullying. Introduzir a problematização dessa questão é o principal objetivo que move a presente escrita, na medida em que abordar as relaçóes cotidianas por meio de categorias é uma forma de enquadramento. As categorias apontam para generalizaçóes, dando um sentido, uma lógica padronizada ao que é explicado por meio delas. Definem as lógicas e os sentidos que constroem as relações, inibindo-lhes outros sentidos possíveis para capturá-las em uma única forma. Forma-fôrma. Usar o termo bullying é uma maneira categórica de enunciar um fato diferente do uso de um conceito ao qual recorremos para analisar ou produzir um acontecimento. Um conceito pode ser utilizado como uma ferramenta que articula ideias e sentidos, sendo multiplicidade, procedendo por corte e recorte, num todo que só 
pode ser fragmentário, como relembram Deleuze e Guattari (1992). Nesse plano, criam-se conceitos frente aos problemas, produzindo fraturas com o nosso tempo. Bullying, em vez de conceito, apresenta-se como categoria para referir uma relação, é uma predefinição e um julgamento de lugares, intençôes e efeitos.

Quando se diz que houve bullying não há mais opçôes, pois as possibilidades das relaçóes humanas que pensaríamos múltiplas são abortadas em favor do seu enquadramento em um único sentido: "foi bullying!". Isto basta. Ficam implícitas as intençóes e as decorrências, perdendo-se completamente as singularidades.

Bullying passou a ser uma repetição, sem diferença. Um modelo de comportamento e de efeitos que, por ser uma forma de enquadramento, não produz curiosidade, dúvida, pois é abordado de forma naturalizada.

A naturalização de relaçóes sociais enquadradas em modelos institucionalizados é uma produção em que estão implícitos modos de subjetividades dominantes. A naturalização é uma prática hermética a novos agenciamentos, à presença de outras formas de vida - institucionalizada ou não - produtoras de rupturas ou, em termos de Guattari, de "modos de singularização" que intervêm nos modelos totalizantes (Scheinvar, 2009, p. 119).

Os acontecimentos, quando enquadrados em uma lógica definida anteriormente à sua existência, perdem sua espontaneidade, as múltiplas lógicas que podem atravessá-los, para serem subsumidos em uma única possibilidade. As relaçóes submetidas a certas normas analíticas têm um sentido a priori, perdendo os possíveis percursos e devires.

A multiplicação de regras, normas, regulamentos, decretos, leis justifica-se em nome da eliminação ou da redução dos conflitos. Entretanto, podemos dizer que tais regras fixas são também produtoras de conflitos, já que, ao se estabelecer uma norma, as relaçóes passam a ser vividas a partir dela, inibindo possibilidades contidas em sua existência. Assim, quando uma criança agride sistematicamente outra, é possível dizer que ela tenha distúrbios, é de uma "natureza má", tem um problema particular com a pessoa alvo da sua agressáo, a pessoa a quem agride a incomoda, está usando essa pessoa para indicar um incômodo que nada tem a ver com o agredido; enfim, inúmeras possibilidades estão postas em face de um ato. Possibilidades, entretanto, abortadas quando abordadas por meio de uma prática que categoricamente define os acontecimentos por meio de um padrão que os antecede.

Um padrão é uma forma homogênea de existir que se reproduz. Tomando desta maneira, identificar uma prática como bullying, além de não considerar as 
singularidades, define lugares fixos para a ação e, nessa medida, para os seus atores. Se o bullying é o enquadramento de uma relação definida como agressiva, há sempre um agente e um submetido. Produz-se uma dicotomia de fácil acesso pela simplificação que opera. Toda dicotomia é um maniqueísmo: é uma maneira de enquadrar e não aprofundar os discursos/práticas e tornar as lógicas presentes na produção de um acontecimento invisíveis e/ou desqualificadas. Em decorrência, o olhar punitivo tem levado a que crianças se perguntem qual a diferença entre brincar e bullying. Se há acontecimentos que serão definidos como bullying, quais os definidos como brincar? A espontaneidade cede lugar para o enquadramento.

Seguindo o pensamento de Foucault, podemos dizer que o bullying se inscreve na lógica da norma, própria das artes de julgar, pois não indica de imediato um julgamento, mas um autocontrole. Coação. Refere uma economia do comportamento, uma maneira do poder manter em permanente tensão estratégias orientadas aos corpos, que são seu objeto.

Como uma nova categoria veiculada para explicar situaçóes problemáticas que acontecem especialmente no espaço escolar, o bullying tem sido elencado entre as chamadas formas de violência, de maneira quase unânime, nos discursos provenientes dos campos médico, jurídico, psi, da mídia e do senso comum, interligando-se para fundamentar a existência desse acontecimento e argumentando a necessidade urgente de combatê-lo.

Para compreendermos como isso vem se processando na atualidade, recusando a ideia de que seja um fenômeno natural que emerge espontaneamente, cabe indagarmos o que produz o bullying como uma nova categoria e também o que o bullying produz. Que forças têm sido acionadas? Nessa direção, podemos assumir uma perspectiva tal como adotada por Foucault em relação aos temas que pesquisou, fazendo uma “ontologia histórica de nós mesmos” e, a partir dela, realizar um diagnóstico e uma crítica de nosso presente.

Assim, inquietarmo-nos com nossos modos de sermos sujeitos e com a emergência do bullying é apostar na descontinuidade, naquilo que faz ruptura, no saber que "é feito para cortar". Preparam-se, nesse sentido, saberes que arguem o que somos, o que sentimos, o que cremos, desestabilizando o instituído para fazer aparecer as forças históricas do processo de sua institucionalização. Entendemos a formação dos saberes que se ocupam da vida humana em termos de poderes, pois se dão em meio a correlaçóes de forças imanentes ao domínio no qual se exercem e são constitutivas da sua organização. Lutas e afrontamentos as transformam, reforçam, invertem, fazem encontrar apoios umas nas outras, formam cadeias ou sistemas, ou ainda, defasagens e contradiçóes que as isolam (Foucault, 1988). 
A medicina e, particularmente, a medicina social, ao valorizar o corpo como objeto de saber, o toma como elemento nas relaçóes de poder. No volume I da História da sexualidade, Foucault (2005) nos mostrou como através do corpo, primeiramente como máquina - a ser adestrado, tendo suas aptidóes ampliadas, sofrendo a extorsão de suas forças que faz crescer sua utilidade e docilidade, sendo, portanto, alvo das disciplinas - institui-se uma anatomopolítica do corpo humano enquanto uma das formas de poder sobre a vida que se desenvolveu a partir do século XVII.

Já por volta da metade do século XVIII, as estratégias de poder tomam o corpo-espécie, perpassado pela mecânica do ser vivo como suporte aos processos biológicos. Os processos vitais e sua possibilidade de variação são assumidos mediante intervençóes e controles reguladores, tais como campanhas de controle de natalidade, vacinação, projetos sobre higiene pessoal, entre outros, tratando-se, então, de uma biopolítica da população. Não só o corpo é controlado, pois a população é atravessada por uma série de dispositivos que orientam as suas possibilidades de existência. A união dos dois eixos, disciplinar e biopolítico, passa a articular o biopoder como poder sobre a vida e sobre a qual se deve investir por meio da sujeição dos corpos e da gestão calculista da população (Foucault, 2002).

$\mathrm{O}$ biopoder se faz fundamental para o desenvolvimento de certa arquitetura do capitalismo, que garante a inserção controlada dos corpos nos aparelhos de produção e opera um ajustamento dos fenômenos da população aos processos econômicos. Por isso constituíram-se na modernidade as preocupaçóes com a saúde, com os modos de se alimentar, de morar, com as condições de vida, enfim, com todo o espaço da existência. Mas é uma preocupação prescritiva, normativa, punitiva, já que efetivamente não se investe na retração das condiçóes responsáveis pela produção daquilo que é tido como "anormalidade" ou inadequação das vidas aos parâmetros construídos na sociedade liberal. Muito pelo contrário: a afirmação do sistema capitalista é produzida com o investimento em normas e padróes que constrangem não só as pessoas, mas sobretudo a população, causando enfrentamento entre os que seguem as normas e os que escapam de tais enquadramentos. Novas formas de governo perceptíveis de modo microfísico, capilarizado pelo tecido social, entraram em ação numa governamentalidade da nação, da família e de si mesmo.

Nesse funcionamento, a atuação da norma assume importância em paralelo à lei e, até mesmo, além e aquém do sistema jurídico da lei. Tornam-se necessários mecanismos contínuos que visam à regulação e à correção. As pessoas e seus comportamentos passam a sofrer os efeitos operados por distribuições em 
torno da norma, de modo que são qualificadas, medidas, avaliadas, hierarquizadas. Com isso, diz Foucault (2005, p.135):

Não quero dizer que a lei se apague ou que as instituições de justiça tendam a desaparecer; mas que a lei funciona cada vez mais como norma, e que a instituição judiciária se integra cada vez mais num contínuo de aparelhos (médicos, administrativos etc.) cujas funçôes são sobretudo reguladoras. Uma sociedade normalizadora é o efeito histórico de uma tecnologia de poder centrada na vida.

Essa importante ressalva nos faz perceber que diferentemente do que se poderia imaginar com o exercício do biopoder, a referência às leis e ao sistema jurídico não diminui: pelo contrário, ela se exacerba. Porém, ao mesmo tempo, exacerbam-se os processos de normalização que, agora, utilizam-se também do saber-poder que provém do campo jurídico, tantas vezes em íntima associação ao saber médico e à norma que ele veicula. Por isso, temos visto tantos apelos à aprovação de novas leis e com consideráveis pedidos em favor do incremento das práticas punitivas. Em nossa sociedade de controle, as penas e os castigos se ampliaram, diz-nos Passetti (2007, p. 135):

a era neoliberal compreende a predominância marcadamente estadunidense decorrente do fluxo conservador voltado para a restauração da família e a ênfase na crença na punição ampliada e nas religiosidades, sustentando algo que se pretende justificar por meio de um suposto recuo na atuação e nos custos do Estado.

\section{Articulaçáo dos discursos médico e jurídico}

A articulação entre os saberes médicos - sobretudo provenientes da psicologia e da psiquiatria - e jurídicos ocorre quando estes se apoiam mutuamente, criando mecanismos de poder híbridos que tentam nos confundir no que diz respeito aos territórios que os configuram e às estratégias por meio das quais sáo acionados. $\mathrm{O}$ argumento mais recorrente em face do que se sentencia como bullying é o do padecimento: a parte definida como agressora é abordada como dotada de distúrbios e, mais do que isto, como uma ameaça futura à sociedade. A parte definida como vítima é abordada em função da determinação de que o evento produz padecimentos. Importa menos a experiência com o que esta com- 
porta de singular e mais o enquadramento que antecede a própria sensação dos envolvidos. Aliás, a sensação é produzida, como toda relação, determinando que certa tensão indique diagnósticos e arbitragens regulamentadas.

Muitas vezes torna-se difícil entender para que se apresentam certas classificaçóes e categorizaçóes, como no caso do bullying, e o que elas propóem. Assim, a categoria bullying comporta tanto vetores de padronização e controle de virtualidades como de punição. Essa tendência, no contemporâneo, mescla formas mais sutis de controle e governo da população e dos indivíduos, adotando estratégias que pareceriam paradoxais e até excludentes que passam a conviver tacitamente e a se justificar uma com base na outra - a exemplo dos programas em que tratamento e punição são associados. Esse movimento de hibridização dos saberes e poderes, que se atravessam, segue os rumos ditados pelo mercado econômico, o qual estende seus tentáculos sobre a figura do Estado, de forma que a gestão estatal e a economia combinam.

A partir do momento em que as populaçóes submetem sua conduta e seus comportamentos cotidianos aos princípios do autoempreendedorismo da teoria do capital humano, elas se tornam presas voluntárias de processos de individuação e de subjetivação controlados flexivelmente pelo mercado (Assis Cesar e Duarte, 2009, p. 122).

O sujeito contemporâneo deve ser um empreendedor de si mesmo, ou seja, deverá almejar e buscar o sucesso pessoal como uma conquista individual que está sob sua responsabilidade. A ideia de uma subjetividade flexível é a própria chave do autocontrole nessa sociedade que, como aponta Deleuze (1992), sem abandonar o modo disciplinar, acopla-se também ao controle sendo o indivíduo estimulado a adquirir competências adequadas à produção de seu capital humano. Para isso, competiçóes e disputas são efeitos que se produzem no plano em que tais ideias se articulam como balizas a novas formas de subjetividades. Dar-lhes visibilidade é parte de uma economia subjetiva afirmativa não daqueles que estão no cerne da relação dita bullying, mas das normas e da lógica punitiva que a circunda. $\mathrm{O}$ acontecimento como espetáculo serve à indicação das pessoas como problemas e à punição como necessidade.

No espaço escolar, a biopolítica atual, que coloca o corpo no centro das atenções, continua a medi-lo e classificá-lo, porém, agora, de acordo com novos índices de vida dita saudável. Os marcadores da normalidade estão mais tênues e a identificação do que escapa dessa norma se dá em nome da prevenção em relação a novos e maiores problemas que poderiam vir a atingir a população, como, por 
exemplo, a obesidade e a violência, ambas alçadas ao patamar de endemias. A que serve o olhar que oferece outro tratamento a certas relaçóes sempre existentes na história, alçando-as à condição de endemias? São formas de escapar a uma subjetividade que se espalha de modo hegemônico, ou uma produção que a fundamenta? Ser "gordo", "brigar" podem ser lidos como resistência ou, antes, como modos de vida. Mas também podem ser produzidos como um problema a ser sanado e até uma ameaça. Trata-se, então, de fechar o cerco contra essas manifestaçóes que diferem do modo subjetivo hegemônico.

A regulação da população se dá por estratégias de poder-saber tendo tanto a ciência quanto os meios de comunicação como aliados. O sensacionalismo tem sido peça-chave para incitar a identificação de ameaças provenientes de si próprio, do vizinho, das relaçóes, inclusive as mais próximas, como aquelas estabelecidas entre colegas de escola. Entre as inúmeras publicaçóes que têm surgido sobre o tema do bullying, torna-se perceptível, de modo geral, o apelo à participação de todos na identificação e no combate dessa forma-inimiga que não se apresenta pelo consenso, mas sim pelo que é apresentado como sendo da ordem do conflito. O inimigo toma forma no corpo de colegas, de alunos, de vizinhos, de amigos, todos enquadrados na condição de agressores e vítimas. As tensóes como possibilidades intelectivas, como dispositivos de construção de novos espaços, novas relações, são impensáveis. Opera-se pela contenção. Toda e qualquer ação vista como conflituosa torna-se intolerável, precisando, mais do que nunca, ser ingenuamente pacificada por novos meios e tecnologias de resolução mediadas por outros, os quais teriam um olhar supostamente diferenciado sobre o que se instituiu como conflito. Esse olhar, entretanto, se constrói pela rotulação, pela segregação das partes e pela previsibilidade de seus destinos.

Afirmaçóes como "o termo bullying pode ser adotado para explicar todo tipo de comportamento agressivo, cruel, proposital e sistemático inerente às relaçôes interpessoais" (Barbosa Silva, 2010, p. 23) trazem a possibilidade interpretativa de uma lente que está preparada para realizar a identificação do bullying em todo comportamento, independentemente de pessoas, histórias, configuraçóes e contextos em que as relaçôes se dão. Paradoxalmente, a pretensão de totalizar e universalizar o bullying reconhece aqueles comportamentos como inerentes às relações humanas. Por um lado os conflitos são vistos como algo natural e que essencialmente acontece em relações interpessoais universais, por outro, assume-se que as relaçóes interpessoais poderiam, de alguma forma, produzir tais comportamentos. Ou seja, os comportamentos se constituem, tornam-se e, portanto, não são, pura e simplesmente, mas podem surpreender a qualquer momento, não obedecendo à ordem "certa" dos acontecimentos ou a "patologias" inerentes aos 
envolvidos. O comportamento definido como bullying é proposto como uma fatalidade para a qual temos que estar preparados com procedimentos padronizados.

A questão que se impóe é que a partir dessa definição seria dada a possibilidade de interpretar e oferecer uma inteligibilidade a algo antes que se anuncie em seus mais diversos atravessamentos. Para além disso, poder-se-ia, entâo, identificar qualquer situação que ainda não tenha acontecido, mas que poderia vir a acontecer, sob a insígnia do bullying. No entanto, há de se pensar que isso não ocorre sem que se capturem muitas forças que estão em jogo, fazendo-as sumir e ficando apenas o olhar que as enquadra sob foco único: bullying. Reforça-se a ideia de aprimorar o olhar da identificação para que ele adquira a capacidade preventiva com pretensóes de controlar a incidência daquele comportamento indesejado.

Comportamento indesejado, neste caso, não é o do pretenso "agressor" apenas, mas também da pretensa "vítima". Ambos emergem de forma despotencializada, fatal: agressor e vítima; ativo e passivo. Não há histórias possíveis, com suas variaçóes, apenas destinos traçados. Assim, acontecimentos que poderiam ser considerados situações-problema viram crime ou doença e são sequestrados em sua condição de serem específicos "com seus alvos, pessoas, intenções, impulsos, razóes e intempestividades" (Passetti, 2007, p. 72). Na lógica dos acoplamentos que visam à obediência, certa inteligibilidade pode se dar pelo diagnóstico e enquadramento no território médico pela via da patologia e do desvio nomeado bullying. No entanto, pode náo se encerrar aí a cadeia compreensiva, sendo esta estrategicamente conduzida à aproximação dos mecanismos jurídicos e da lógica-vizinha que a encaminha ao tribunal, seja ele judicial, escolar, familiar ou tutelar.

Nesse contexto, o tribunal como imagem-lugar-condição que procede à identificação de pessoas como vítimas e réus institui um microprocesso judicial no interior da vida que vai a julgamento, o que pode acarretar a culpabilização e a punição do vivente. A categoria bullying passa a operar como o que dá nome estrangeiro a práticas locais que perdem sua potência de veicular algo (im)próprio para ser enquadrado como inapropriado, desviante, violento, criminoso, enfim passível de julgamento e punição, e que incrementa os movimentos de judicialização da vida no contemporâneo.

\section{Referências}

Assis César, M. R., \& Duarte, A. (2009). Governo dos corpos e escola contemporânea: Pedagogia do fitness. Educação e Realidade, 34(2), 119-134.

Psic. Clin., Rio de Janeiro, vol. 26, N.2, P. 87 - I04, 2014 
Barbosa Silva, A. B. (2010). Bullying: mentes perigosas nas escolas. Rio de Janeiro: Objetiva.

Chalita, G. (2008). Pedagogia da amizade - bullying: o sofrimento das vitimas e dos agressores. São Paulo: Gente.

Craig, W. M, \& Harel, Y. (2004). Bullying, physical fighting and victimization. In C. Currie et al. (Eds.). Young people's health in context. Health behaviour in school-aged children (HBSC) study: international report from the 2001/2002 survey (pp. 133- 144). Copenhagen: World Health Organization. Recuperado em 10 de janeiro, 2013, de <http://www.euro. who.int/_data/assets/pdf_file/0008/110231/e82923.pdf>.

Deleuze, G. (1992). Post-Scriptum sobre as sociedades de controle. In G. Deleuze. Conversaçóes: 1972-1990 (pp. 219-226). Rio de Janeiro: Editora 34.

Deleuze, G., \& Guattari, F. (1992). O que é a filosofia?. Lisboa: Editorial Presença.

Fante, C., \& Pedra, J. (2008). Bullying escolar: perguntas \& respostas. Porto Alegre: Artmed.

Ferraz, S. F. S. (2008). Comportamentos de bullying: estudo numa escola técnico-profissional.

(Dissertação de Mestrado em Psicologia Forense. Curso de Pós-Graduação do Instituto Nacional de Medicina Legal, Universidade do Porto, Porto, Portugal).

Foucault, M. (1988). Microfísica do poder. Rio de Janeiro: Graal.

Foucault, M. (2002). Em defesa da sociedade. São Paulo: Martins Fontes.

Foucault, M. (2005). História da sexualidade, v. 1: A vontade de saber. Rio de Janeiro: Graal.

Olweus, D. (1993). Bullying at school: what we know and what we can do. Oxford UK \& Cambridge USA: Blackwell.

Passetti, E. (2007). Direitos Humanos, sociedade de controle e a criança criminosa. In Consetho Regional de Psicologial RJ (Org.). Direitos Humanos? O que temos a ver com isso? (pp. 63-82). Rio de Janeiro: Conselho Regional de Psicologia - RJ.

Scheinvar, E. (2009). O feitiço da política pública. Escola, sociedade civil e direitos da criança e do adolescente. Rio de Janeiro: Lamparina Editores.

\section{Notas}

${ }^{1}$ Tal citação à cultura dos Estados Unidos não deve desconsiderar que as primeiras pesquisas sobre o tema ocorreram nos anos de 1970 na Noruega, ganhando maior visibilidade em outros países a partir do final dos anos de 1990.

${ }^{2}$ Discussão baseada no texto "Judicialização da vida escolar: o bullying como dispositivo analisador", pesquisa de doutorado de uma das autoras (em andamento).

${ }^{3}$ A escola é o espaço privilegiado, mas sua identificação é mais ampla, por exemplo, aparecendo na rede web quando é denominado cyberbulliyng. 
${ }^{4}$ A Lei Ordinária No 4725, de 15 de março de 2006 "autoriza o poder executivo a criar obrigação de notificação compulsória, nos casos de violência contra criança e adolescente, quando atendidos nos serviços de saúde públicos e privados do estado do Rio de Janeiro".

Recebido em 28 de novembro de 2012 Aceito para publicação em 22 de janeiro de 2013 